UNDERGROUND MINING ENGINEERING 34 (2019) 11-25 $\quad$ UDK 62

Original scientific paper

\title{
CORRELATION OF UNIAXIAL COMPRESSIVE STRENGTH WITH THE DYNAMIC ELASTIC MODULUS, P - WAVE VELOCITY AND S - WAVE VELOCITY OF DIFFERENT ROCK TYPES
}

\author{
Jelena Majstorović ${ }^{1}$, Miloš Gligorić1 ${ }^{1}$, Suzana Lutovac ${ }^{1}$, Milanka Negovanović ${ }^{1}$, \\ Luka Crnogorac ${ }^{1}$
}

Received: March 3, 2019

Accepted: May 12, 2019

\begin{abstract}
Knowing mechanical properties of rocks incorporated with ultrasonic waves velocities investigations provide a secure basis for mine modelling. Uniaxial compressive strength, dynamic elastic modulus and ultrasonic waves velocities are just some of the rock properties that indicate on presence of discontinuities, stratification and fissures of rocks. Determining the relationship of these rock properties testing the rock samples that are corresponding to different rock types extracted from different mineral deposits represents the core of this study.

In this paper, we statistically analyzed measured and calculated rock properties. We established the connection between these parameters creating empirical correlation equations. Using least squares method and simple linear regression analysis, we defined correlation coefficients and also developed empirical correlation equations.
\end{abstract}

Keywords: linear regression analysis; least squares method; dynamic elastic modulus; ultrasonic waves velocities;

\section{INTRODUCTION}

Capital objects such as infrastructure facilities, surface and underground structures, tunnels, mine rooms and pillars etc. primarily depend on physical and mechanical rock properties. In order to plan and design any of these structures, the investigation of the relationships of the rock properties plays a vital role. Different rock types indicate different rock properties and it is very important to find correlation and similarity of them. Based on this, determination the connectivity between rock properties that are correspond to different rock types extracted from the different mineral deposits represent reliable basis for mine modelling.

Many researchers studied physical and mechanical properties of different rock types with destructive and non - destructive test methods and made reasonable correlations between

\footnotetext{
${ }^{1}$ University of Belgrade - Faculty of Mining and Geology

Emails: jelena.majstorovic@ rgf.bg.ac.rs, milos.gligoric@ @rgf.bg.ac.rs, suzana.lutovac@ @rgf.bg.ac.rs, $\underline{\text { milanka.negovanovic@ rgf.bg.ac.rs, luka.crnogorac@ rgf.bg.ac.rs }}$
} 
the properties. They are investigate relationships of the following rock properties such as uniaxial compressive strength UCS and $\mathrm{P}$ - wave velocity $\mathrm{V}_{\mathrm{p}}, \mathrm{V}_{\mathrm{p}}$ and density, UCS and dynamic elastic modulus $\mathrm{E}_{\mathrm{dyn}}, \mathrm{UCS}$ and porosity, $\mathrm{V}_{\mathrm{p}}$ and porosity, $\mathrm{E}_{\mathrm{dyn}}$ and density etc. All of these relationships showed different levels of correlation. High number of empirical equations that are related to rock properties investigation is developed for estimate the mechanical rock properties.

Determination of the correlations between uniaxial compressive strength UCS and other physical and mechanical rock properties such as $\mathrm{P}$ - wave velocity, shear wave velocity, elastic modulus, density and permeability for different rock types such as limestone, sandstone, coal, travertine, dolomite, and other rock types are widely studied (Tugrul and Zarif, 1999; Yagiz, 2011; Diamantis et al., 2011; Minaeian and Ahangari, 2013; Pappalardo et al., 2016; Inoue and Ohomi, 1981; Aşc1 et al., 2017).

Also, many authors investigate the $P$ - wave velocity correlated with density, Young's modulus, uniaxial compressive strength UCS, tensile strength, Poisson's ratio, impact strength index etc. (Khandelwal and Singh, 2009; Yasar and Erdogan, 2004)

Empirical equations, obtained from the correlation between mechanical properties of the different rock types, have been developed to predict uniaxial compressive strength from other mechanical properties (Sharma and Singh, 2008; Singh et al., 2012; Rajabi et al., 2017; Kahraman, 2001)

In our paper, we have created a correlation between uniaxial compressive strength UCS with dynamic elastic modulus $E_{d y n}, P$ - wave velocity $V_{p}$ and $S$ - wave velocity $V_{s}$. These rock properties are measured and calculated depending on laboratory investigations. Uniaxial compressive strength is determined by universal machine hydraulic press. Dynamic elastic modulus is computed by several equations related to $P$ - waves, $S$ - waves, density and dynamic Poisson's ratio. $P$ - wave and $S$ - wave velocities are measured using the instrument - SONIC VIEWER. Using least squares method and simple linear regression analysis, we defined empirical correlation equations with correlation coefficients between these relationships. Obtained correlation coefficients show us very high strength of correlation between these rock properties. It should be noted that five different rock types extracted from the seven different mineral deposits are applied for investigation. Because there are a seven mineral deposits with different number of tested samples, we determined mean values of each rock properties and represent obtained results through the tables and figures.

\section{ROCK PROPERTIES AND LABORATORY INVESTIGATIONS}

The rock samples are taken from seven different mineral deposits (deposit $1-\mathrm{D} 1$, deposit $2-D 2, \ldots$, deposit $7-D 7$ ). The total number of rock samples is 31 . From these mineral deposits, five different rock types are extracted such as dolomite, dacitic tuff, dolomitic marble, limestone and granite. Each of these rock types has several rock 
samples that are investigated and number of these rock samples is various depending of rock type. On each of the rock sample, the following rock properties are measured and determined and they are uniaxial compressive strength, ultrasonic waves velocities $(P$ waves and $S$ - waves velocities) and dynamic elastic modulus. Because there are seven different mineral deposits with different number of rock samples, we have calculated mean values for each of the rock properties from the appropriate mineral deposit.

\section{$\underline{P}$-waves and $S$-waves test}

The waves propagation velocities ( $\mathrm{P}$ - waves and $\mathrm{S}$ - waves) were measured using the SONIC VIEWER, model 5210. P - wave velocities represent the primary or longitudinal elastic wave velocities. $\mathrm{S}$ - wave velocities represent secondary or transversal elastic wave velocities. The role and significance of ultrasound testing is particularly important because it is without damage of stone sample (nondestructive method) and sample can be used for other treatments with destruction (Majstorović and Cvetković, 2004).

\section{$\underline{\text { Uniaxial compressive strength test }}$}

For UCS investigation, rock samples are used in the form of cylindrical cores extracted from boreholes. Dimensions of the rock samples are adapted to the tested rock parameter. Typical size of the rock sample is given as ratio $h / d \cong 1$ where $h$ represents the height of the rock sample and $d$ represents the diameter of the rock sample. The value of this ratio indicates that the height and diameter of the rock sample are approximately equal.

When dimensions of the rock samples are defined, next step is related to main test of this rock parameter. The main test is performed using a universal machine that designed for this testing called hydraulic press. This press has a high power of $2000 \mathrm{kN}$ and it can be used for other investigations of the mechanical rock properties. Prepared rock samples are placed between the platens of the hydraulic press and axially loaded until fracture. Because this investigation causes damage and fracture of the rock samples this test corresponds to destructive methods.

\section{Dynamic elastic modulus}

Since standard sample preparation is time consuming and expensive, indirect tests are also often conducted to estimate the elastic modulus using empirical correlations.

In order to determine dynamic elastic modulus, rock samples are prepared on the same way as for UCS investigation. Also, dimensions and size of the rock samples are identical as for UCS investigation. The propagation velocity of elastic waves measured on intact rock is usually used to calculate the dynamic elastic properties (Zhang, 2005). Therefore, the dynamic elastic modulus is computed by applying several equations related to $P-$ waves, $S$ - waves, density and dynamic Poisson's ratio as follows: 


$$
\begin{gathered}
E_{d y n}=V_{p}^{2} \cdot \rho \cdot \frac{\left(1+\mu_{d y n}\right) \cdot\left(1-2 \cdot \mu_{d y n}\right)}{1-\mu_{d y n}} \\
\alpha=\frac{V_{p}}{V_{s}} \\
\mu_{d y n}=\frac{2 \cdot \alpha^{2}-1}{2 \cdot \alpha^{2}-2}
\end{gathered}
$$

Where:

$V_{p}$ - longitudinal elastic waves propagation velocities ( $\mathrm{P}$ - waves)

$V_{s}$ - transversal elastic waves propagation velocities ( $\mathrm{S}$ - waves)

$\mu_{d y n}$-dynamic Poisson's ratio

$\rho$ - density

$\alpha-$ ratio of the velocities

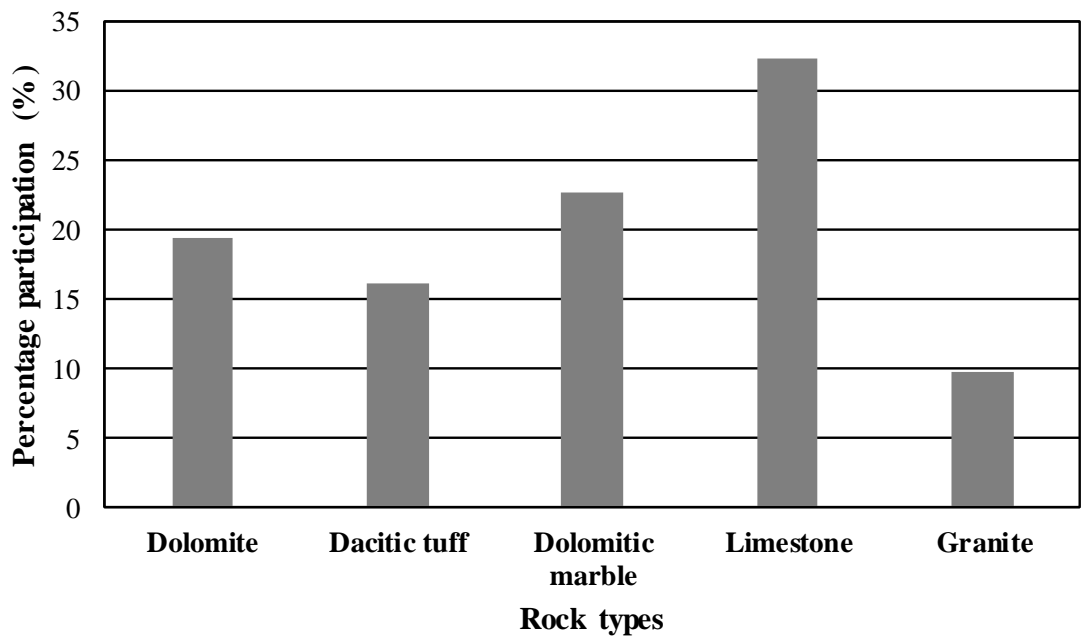

Figure 1 Percentage participation of the tested rock types 
Figure 1 shows a percentage participation of the five different rock types that were included in the examination test. These tested rock types are extracted according to the genesis of the rock (magmatic, metamorphic and sedimentary). Limestone occupy the most part of the tested rock samples with $32,26 \%$, and granite is the smallest with only $9,68 \%$. Dolomite, dacitic tuff and dolomitic marble participate in the testing process with approximately same quantities of $19,35 \%, 16,13 \%$ and $22,58 \%$, respectively.

Correlation coefficient - verbal classification is represented in Table 1 (Singh, 2018; Nangolo and Musingwini, 2011). This classification is based on five different ranges. Each range is determined by corresponding verbally description and contains clearly defined boundaries. Obtained results are grouped into one of the defined ranges and indicate the strength of the correlation given as the absolute value.

Table 1 Correlation coefficient - verbal classification (Singh, 2018; Nangolo and Musingwini, 2011)

\begin{tabular}{cc}
\hline $\begin{array}{c}\text { Correlation coefficient }- \\
\text { verbal classification }\end{array}$ & $\begin{array}{c}\text { Correlation coefficient }- \\
\text { Value }\end{array}$ \\
\hline Very weak & $0.00-0.19$ \\
Weak & $0.20-0.39$ \\
Moderate & $0.40-0.59$ \\
Strong & $0.60-0.79$ \\
Very strong & $0.80-1.00$ \\
\hline
\end{tabular}

$\mathrm{P}$ - wave velocity classification is shown in Table 2 (Yagiz, 2011; Anon, 1979). This classification describes five different rock classes with respect to $\mathrm{P}$ - wave velocity. Each class corresponds to the specific description and a defined range of $\mathrm{P}$ - wave velocity. Our tested results belong to the one of these rock classes. Using this classification, we can conclude that low values of $\mathrm{P}$ - wave velocity corresponds to low values of UCS while high values of $\mathrm{P}$ - wave velocity corresponds to high values of UCS. Using this classification, we can conclude that our obtained mean values of $\mathrm{P}$ - wave velocities from each mineral deposit belong to following descriptions: D1 - high, D2 - moderate, D3 - high, D4 - moderate, D5 - very high, D6 - high and D7 - very high. 
Table 2 P - wave velocity classification (Yagiz 2011; Anon 1979)

\begin{tabular}{cc}
\hline $\boldsymbol{V}_{\boldsymbol{p}}(\mathbf{m} / \mathbf{s})$ & Description \\
\hline$<2500$ & Very low \\
$2500-3500$ & Low \\
$3500-4000$ & Moderate \\
$4000-4500$ & High \\
$>4500$ & Very high \\
\hline
\end{tabular}

\section{SIMPLE REGRESSION ANALYSIS}

A main objective of regression analysis is to estimate the unknown parameters in the regression model. This process is also called fitting the model to data. Simple regression analysis is one of the most important and most applied technique for the statistical data testing. The main task of this analysis is to create relationship between two variables and express that relationship by regression line. After regression line is drawn, connection between these variables is represented as mathematical equation.

There are two model types of regression analysis: linear and nonlinear. In our study, we applied linear regression analysis as the most preferred approach in regression analysis. There are different types of linear regression analysis: simple linear regression, multiple linear regression, logistic regression, ordinal regression, multinomial regression and discriminant analysis (Ghani and Ahmad 2010). Simple and multiple regressions are the most widely used and well explained methods in literature (Allison, 1998; Kisi and Ozkan, 2017).

Measured values are analyzed by simple linear regression and least squares method. Based on this, correlation coefficients $R^{2}$ are determined for each relationship. Further that, empirical correlation equations are defined for each relationship of the rock properties.

In statistics, linear regression is a linear approach to modelling the relationship between a dependent variable and one or more independent variables. (Keles, 2018; Kowal, 2016; Guerard, 2013) Empirical equation of the simple linear regression is given as follows: 


$$
Y=a X+b
$$

Where:

$\mathrm{Y}$ - is the dependent variable of the linear function,

$\mathrm{X}$ - is the independent variable,

$\mathrm{a}-$ is the slope of the line,

$\mathrm{b}-$ is the $\mathrm{y}$ - intercept

The parameters $\mathrm{a}$ and $\mathrm{b}$ characterized the slope and intercept of the regression analysis, respectively, drawing the regression line. These parameters will be derived from the least squares application.

Using least squares method, values a and b are calculated as follows:

$$
\begin{array}{cc}
a=\frac{N \cdot\left(\sum_{i=1}^{N} X_{i} \cdot Y_{i}\right)-\left(\sum_{i=1}^{N} X_{i} \cdot \sum_{i=1}^{N} Y_{i}\right)}{N \cdot\left(\sum_{i=1}^{N} X_{i}^{2}\right)-\left(\sum_{i=1}^{N} X_{i}\right)^{2}} & i=1, \ldots, N \\
b=\frac{\left(\sum_{i=1}^{N} Y_{i} \cdot \sum_{i=1}^{N} X_{i}^{2}\right)-\left(\sum_{i=1}^{N} X_{i} \cdot \sum_{i=1}^{N} X_{i} \cdot Y_{i}\right)}{N \cdot\left(\sum_{i=1}^{N} X_{i}^{2}\right)-\left(\sum_{i=1}^{N} X_{i}\right)^{2}} & i=1, \ldots, D \\
& N=1, \ldots, D
\end{array}
$$

The correlation coefficient $R^{2}$ represents the percentage of the variance of the dependent variable explained by the independent variable. The correlation coefficient cannot exceed 1 nor be less than zero. In the case of $R^{2}=0$, the regression line's Y $=\mathrm{Y}$ and no variation in the dependent variable are explained. (Guerard, 2013)

Correlation coefficient $R^{2}$ can be computed as:

$$
R^{2}=\frac{N \cdot\left(\sum_{i=1}^{N} X_{i} \cdot Y_{i}\right)-\left(\sum_{i=1}^{N} X_{i} \cdot \sum_{i=1}^{N} Y_{i}\right)}{\sqrt{\left[N \cdot\left(\sum_{i=1}^{N} X_{i}^{2}\right)-\left(\sum_{i=1}^{N} X_{i}\right)^{2}\right] \cdot\left[N \cdot\left(\sum_{i=1}^{N} Y_{i}^{2}\right)-\left(\sum_{i=1}^{N} Y_{i}\right)^{2}\right]}} \quad \begin{aligned}
& i=1, \ldots, N \\
& N=1, \ldots, D
\end{aligned}
$$




\section{DATA ANALYSIS AND GRAPHICAL REVIEW}

Number of tested samples of the corresponding rock type varies from 3 (granite - deposit 5) to 7 (dolomitic marble - deposit 3). Number of the other tested samples of the corresponding rock type is: 6 (dolomite - deposit 1), 5 (dacitic tuff - deposit 2), 3 (limestone - deposit 4), 4 (limestone - deposit 6) and 3 (limestone - deposit 7). A total of 31 samples were tested and included in the investigation process.

Because there are a seven mineral deposits with different number of tested samples, we determined mean values of each rock properties. Mean values of rock properties of the corresponding mineral deposit are presented in Table 3.

Table 3 Mean values of rock properties for each mineral deposit

\begin{tabular}{ccccc}
\hline & $U C S_{s r}(\mathrm{MPa})$ & $E_{d y n s r}(\mathrm{GPa})$ & $V_{P_{s r}}(\mathrm{~m} / \mathrm{s})$ & $V_{S s r}(\mathrm{~m} / \mathrm{s})$ \\
\hline D1 & 77.99 & 30.01 & 4160.00 & 2050.00 \\
D2 & 41.58 & 19.02 & 3632.00 & 1772.00 \\
D3 & 100.74 & 32.74 & 4424.29 & 2065.71 \\
D4 & 55.97 & 26.13 & 3903.33 & 1910.00 \\
D5 & 130.08 & 46.35 & 4723.33 & 2548.89 \\
D6 & 64.45 & 30.58 & 4280.00 & 2047.50 \\
D7 & 110.71 & 41.07 & 4970.00 & 2383.33 \\
\hline
\end{tabular}

At the following figures, tested rock samples from the corresponding mineral deposits are marked as different colors considering two analyzed rock properties.

Distribution of the total number of tested samples from the all mineral deposits considering to uniaxial compressive strength UCS versus dynamic elastic modulus $E_{d y n}$ is shown in Figure 2. As you can see from this figure, correlation between these two parameters are visible. The data are grouped to form a linear relationship.

Correlation of the mean values of uniaxial compressive strength $U C S_{s r}$ and dynamic elastic modulus $E_{d y n s}$ considering to all tested samples from the all mineral deposits is represented in Figure 3. 


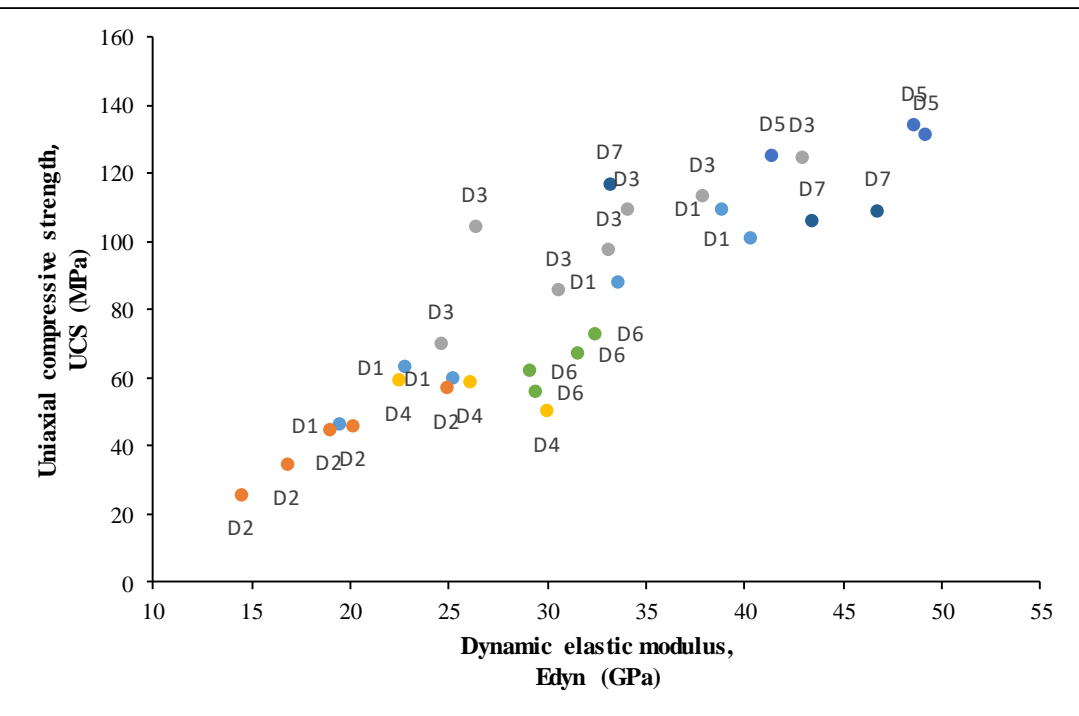

Figure 2 Distribution of the total number of tested samples from the all mineral deposits considering to uniaxial compressive strength UCS versus dynamic elastic modulus $E_{d y n}$

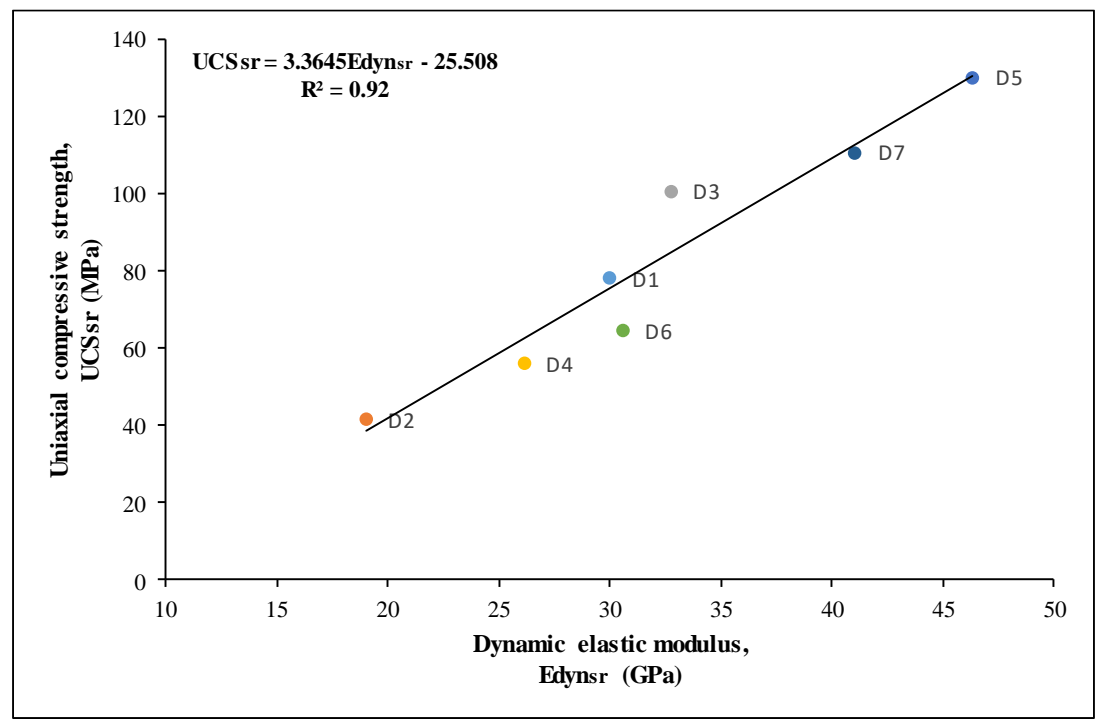

Figure 3 Correlation of the mean values of uniaxial compressive strength $U C S_{s r}$ and dynamic elastic modulus $E_{d y n s}$ considering to all tested samples from the all mineral deposits 
Correlation coefficient of $R^{2}=0.92$ indicates that there is a very strong relationship between these two rock parameters (see Table 1). Linear regression equation for the relationship between $U C S_{s r}$ and $E_{d y n s}$ is given as follows:

$$
U C S_{s r}=3,3645 \cdot E_{d y n s r}-25,508 \quad R^{2}=0,92
$$

Figure 4 represents distribution of the total number of tested samples from the all mineral deposits considering to uniaxial compressive strength UCS versus $\mathrm{P}$ - wave velocity V_p. Correlation between these two parameters of tested samples is also obviously. It can be concluded that set of data create a linear relationship.

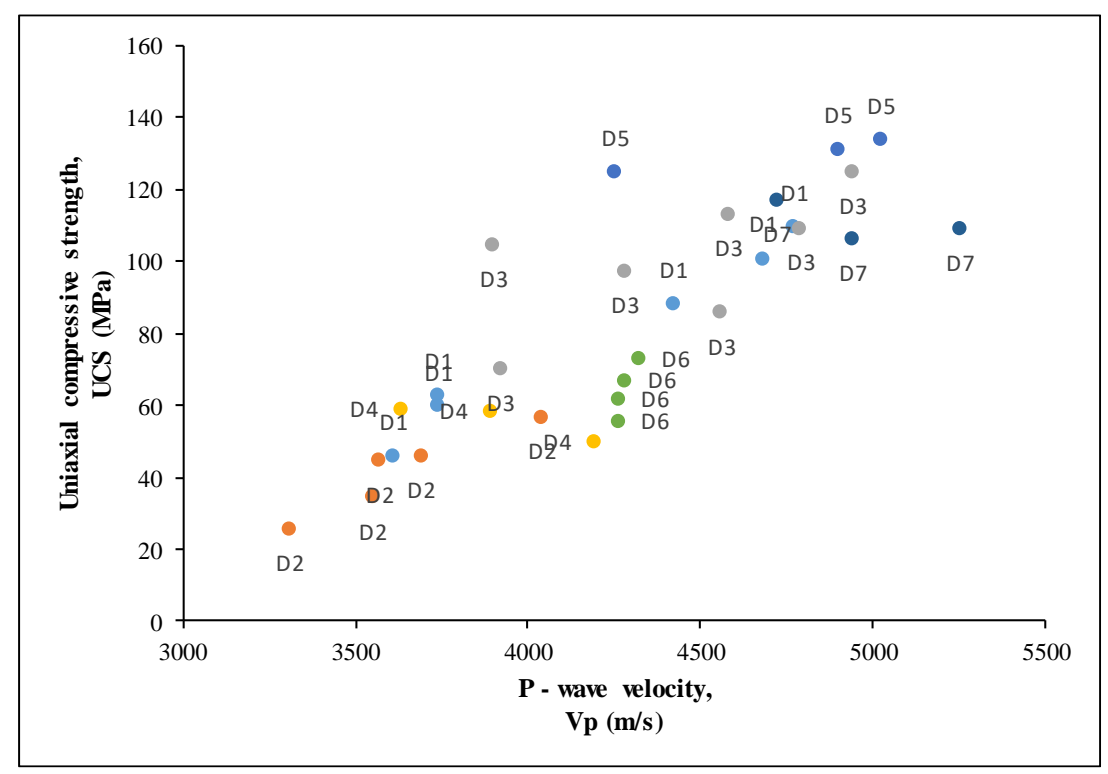

Figure 4 Distribution of the total number of tested samples from the all mineral deposits considering to uniaxial compressive strength UCS versus $\mathrm{P}$ - wave velocity Vp

Correlation of the mean values of uniaxial compressive strength $U C S_{s r}$ and $\mathrm{P}$ - wave velocity $V_{p s r}$ considering to all tested samples from the all mineral deposits is represented in Figure 5. 


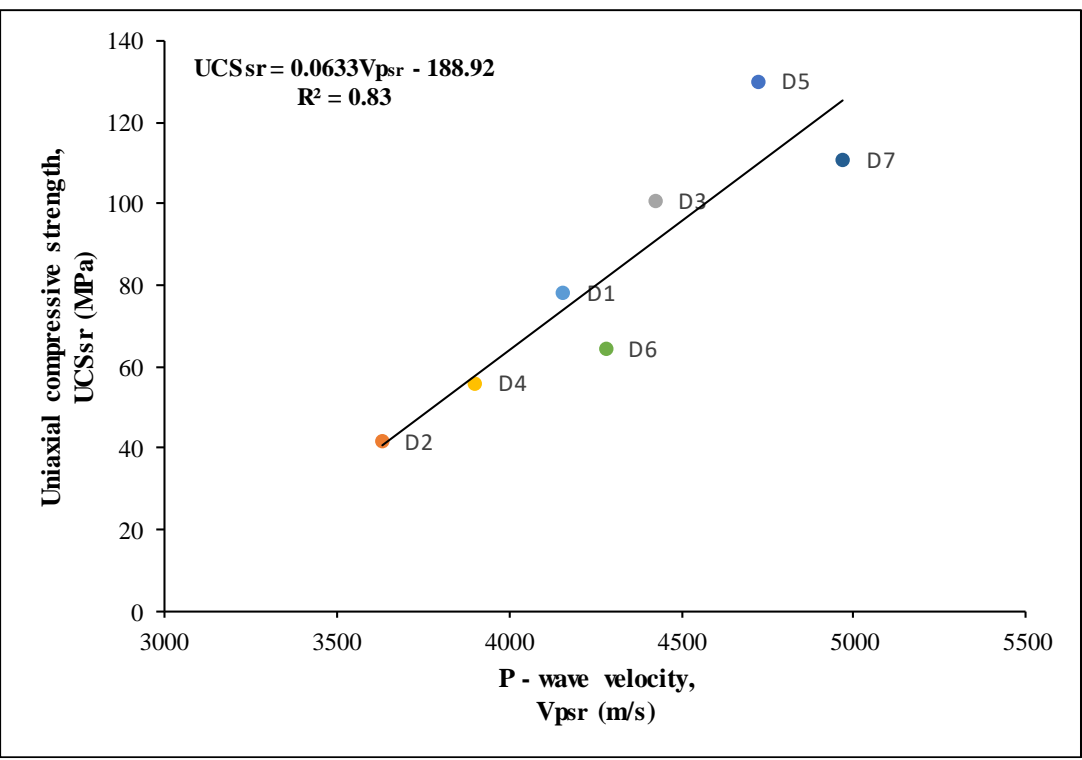

Figure 5 Correlation of the mean values of uniaxial compressive strength $U C S_{s r}$ and $\mathrm{P}$ - wave velocity $V_{p s r}$ considering to all tested samples from the all mineral deposits

Correlation coefficient of $R^{2}=0.83$ indicates that there is also exist a very strong relationship between these two rock parameters. Comparing with previous correlation coefficient between $U C S_{s r}$ and $E_{d y n s}$ of $R^{2}=0.92$ this coefficient is less than him that shows a lower relationship but still high level of correlation. As it mentioned earlier, linear regression equation is also applied to describe relationship between $U C S_{s r}$ and $V_{p s r}$. It gives as:

$$
U C S_{s r}=0,0633 \cdot V_{p s r}-188,92 \quad R^{2}=0,83
$$

Figure 6 shows distribution of the total number of tested samples from the all mineral deposits considering to uniaxial compressive strength UCS versus $\mathrm{S}$ - wave velocity Vs. As it can be seen from the Figure 2 and Figure 4, set of data are also organized to make linear connectivity between these two parameters. 


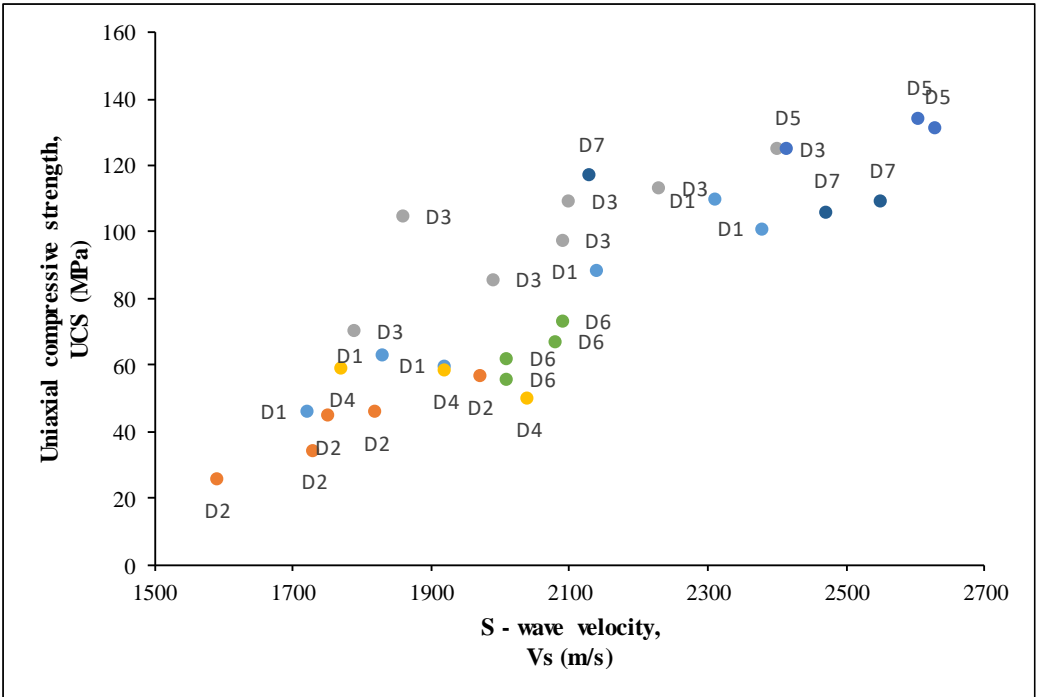

Figure 6 Distribution of the total number of tested samples from the all mineral deposits considering to uniaxial compressive strength UCS versus $\mathrm{S}$ - wave velocity Vs

Figure 7 shows correlation of the mean values of uniaxial compressive strength $U C S_{s r}$ and $\mathrm{S}$ - wave velocity $V_{S s r}$ considering to all tested samples from the all mineral deposits.

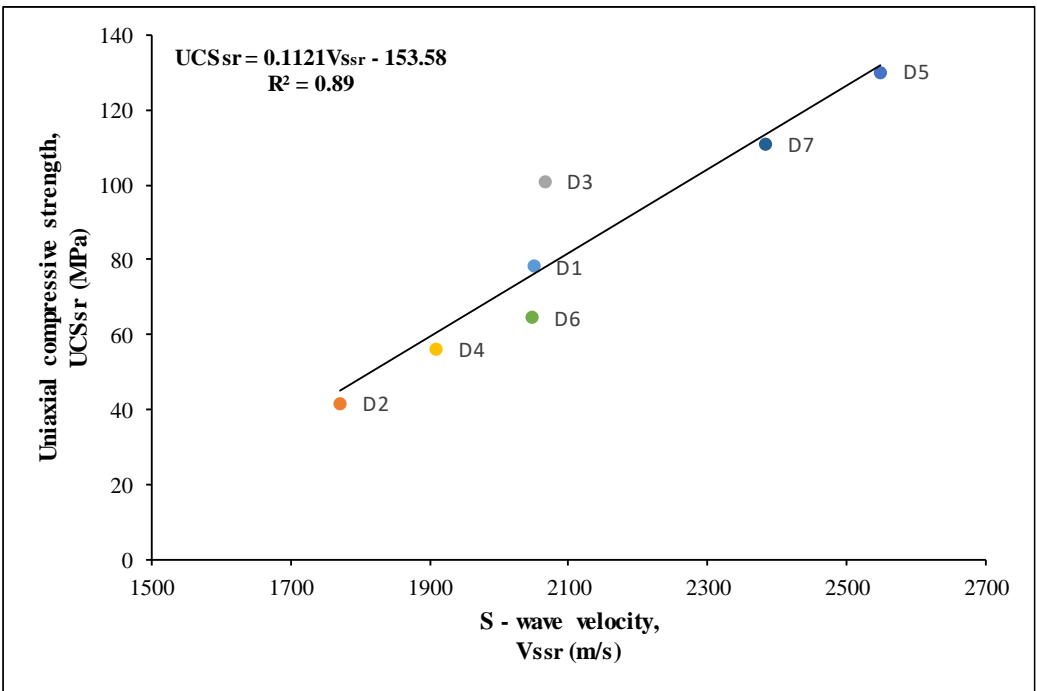

Figure 7 Correlation of the mean values of uniaxial compressive strength $U C S_{s r}$ and $\mathrm{S}$ - wave velocity $V_{S s r}$ considering to all tested samples from the all mineral deposits 
Correlation coefficient of $R^{2}=0.89$ also indicates a very strong relationship between these two rock parameters. Comparing with correlation coefficient between $U C S_{s r}$ and $E_{d y n s}$, this correlation coefficient is less than him. On the other side, comparing with correlation coefficient between $U C S_{s r}$ and $V_{P s r}$, this correlation coefficient is greater than him. It means that this correlation coefficient also has a high level of the correlation. Linear regression analysis is applied again above this set of data and determined the level of the relationship. Linear regression is given as following equation:

$$
U C S_{s r}=0,1121 \cdot V_{s s r}-153,58 \quad R^{2}=0,89
$$

\section{CONCLUSION}

UCS is one of the most important physical and mechanical properties of every rock type. By developing the relationship between UCS and other rock properties, we have created a basis for prediction model of these rock properties based on UCS.

In this paper, the mean values of the uniaxial compressive strength are correlated with the mean values of the other rock properties. Correlation coefficient of the mean values of uniaxial compressive strength $U C S_{s r}$ and dynamic elastic modulus $E_{d y n s r}$ considering to all tested samples from the all mineral deposits is 0.92 . It indicates that relationship between these two rock parameters is very strong. Comparing with other correlation coefficient, it is clearly visible that relationship between these two rock parameters is the best one. Since that $E_{d y n s}$ is calculated on the basis of the both ultrasonic waves velocities ( $\mathrm{P}$ - wave and $\mathrm{S}$ - wave) and density, this analysis gives high strength of correlation with respect to the relationships between $U C S_{s r}$ versus $V_{P s r}$ and $U C S_{s r}$ versus $V_{S s r}$.

\section{Acknowledgement}

This paper is a part of the Projects TR 36014 and TR 33029 under the auspices of the Ministry of Education, Science and Technological Development, Republic of Serbia. 


\section{REFERENCES}

ALLISON P.D. (1998) Multiple regression: a primer. Thousand Oaks, Calif.: Pine Forge Press.

AŞCI M. et al. (2017) Correlation of physical and mechanical properties with ultrasonic pulse velocities of sandstones in Çenedağ, Kocaeli-Turkey. International Journal of Advanced Geosciences, 5 (2), pp. 109-115.

ANON (1979) Classification of rocks and soils for engineering geological mapping. Bulletin of the International Association of Engineering Geology, 19, pp. 364 - 371.

DIAMANTIS K. et al. (2011) Correlating wave velocities with physical, mechanical properties and petrographic characteristics of peridotites from the central Greece. Geotechnical and Geological Engineering, 29(6), pp. 1049-1062.

GHANI I.M.M. and AHMAD S. (2010) Stepwise multiple regression method to forecast fish landing. In: International Conference on Mathematics Education Research 2010, Procedia Social and Behavioral Sciences, 8, pp. 549-554.

GUERARD J. (2013) Introduction to financial forecasting in investment analysis. Springer.

INOUE M. and OHOMI M. (1981) Relation between uniaxial compressive strength and elastic wave velocity of soft rock. In: Proceedings of the International Symposium on Weak Rock, Tokyo, pp. 9-13.

KAHRAMAN S. (2001) Evaluation of simple methods for assessing the uniaxial compressive strength of rock. International Journal of Rock Mechanics and Mining Sciences, 38, pp. 981-994.

KELES T. (2018) Comparison of Classical Least Squares and Orthogonal Regression in Measurement Error Models. International Online Journal of Educational Sciences, 10 (3), pp. $200-214$.

KISI O. and OZKAN C. (2017) A New Approach for Modeling Sediment-Discharge Relationship: Local Weighted Linear Regression. Water Resources Management, 31, pp. $1-23$.

KOWAL R. (2016) The Efficiency of OLS Estimators of Structural Parameters in a Simple Linear Regression Model in the Calibration of the Averages Scheme. Folia Oeconomica Stetinensia, pp. 236 - 249.

KHANDELWAL M. and SINGH T.N. (2009) Correlating static properties of coal measures rock with P-wave velocity. International Journal of Coal Geology, 44, pp. 55- 60 . 
MAJSTOROVIĆ J. and CVETKOVIĆ M. (2004) Some results of stone testing as working environment by ultrasound. In: ECRBM '04 (European Conference on Raw Building Materials and Coal: New Perspectives), Sarajevo.

MINAEIAN B. and AHANGARI K. (2013) Estimation of uniaxial compressive strength based on P-wave and Schmidt hammer rebound using statistical method. Arabian Journal of Geosciences, 6, pp. 1925-1931.

NANGOLO C. and MUSINGWINI C. (2011) Empirical correlation of mineral commodity prices with exchange - traded mining stock prices. The Journal of the Southern African Institute of Mining and Metallurgy, 111, pp. 459 - 468.

PAPPALARDO G. et al. (2016) Geotechnical characterization of limestone employed for the reconstruction of a UNESCO world heritage baroque monument in southeastern Sicily (Italy). Engineering Geology, 212, pp. 86-97.

RAJABI A.M. et al. (2017) The New Empirical Formula to Estimate the Uniaxial Compressive Strength of Limestone; North of Saveh a Case Study. Journal of Engineering Geology, 11, No. 3, pp. 159-180.

SINGH M. P. (2018) Efficient Multi-site Statistical Downscaling Model for Climate Change. Thesis (PhD), Motilal Nehru National Institute Of Technology Allahabad Prayagraj.

SINGH T. N. et al. (2012) Correlation Between Point Load Index and Uniaxial Compressive Strength for Different Rock Types. Rock Mechanics and Rock Engineering, 45(2), pp. 259-264.

SHARMA P. K. and SINGH, T. N. (2008) A correlation between P-wave velocity, impact strength index, slake durability index and uniaxial compressive strength. Bulletin of Engineering Geology and the Environment, 67, pp. 17-22.

TUGRUL A. and ZARIF I. H. (1999) Correlating of mineralogical and textural, characteristics with engineering properties of selected granitic rocks from Turkey. Engineering Geology, 51, pp. 303-317.

YAGIZ S. (2011) P-wave velocity test for assessment of geotechnical properties of some rock materials. Bulletin of Materials Science, 34(4), pp. 947-953.

YASAR E. and ERDOGAN Y. (2004) Correlating sound velocity with the density, compressive strength and Young modulus of carbonate rocks. International Journal of Rock Mechanics and Mining Sciences, 41, pp. 871-875.

ZHANG L. (2005) Engineering properties of rocks. Oxford: Elsevier. 